\title{
Article
}

\section{Synthesis of nickel nanoparticles by sol-gel method and their characterization}

\author{
Aisha Shamim ${ }^{1}$, Zaheer Ahmad ${ }^{1, *}$, Sajid Mahmood ${ }^{2}$, Umair Ali ${ }^{2}$, Tariq Mahmood ${ }^{3}$ and Zamir Ahmad \\ Nizami $^{4}$ \\ 1 Department of Chemistry, University of Wah, Wah Cantt 47040, Pakistan. \\ 2 Department of Chemistry, Division of Science and Technology, University of Education, Township Campus, Lahore, \\ Pakistan. \\ 3 Nano Sciences and Technology Department, National Centre for Physics, QAU, Islamabad 45320, Pakistan. \\ 4 Department of Chemistry, University of Sargodha,Sub Campus Bhakkar, Pakistan. \\ * Correspondence: dr.zaheer.ahmad@uow.edu.pk; Tell: +92-3322569362
}

Received: 25 January 2019; Accepted: 9 February 2019; Published: 30 June 2019.

\begin{abstract}
The under consideration study focuses on synthesis and characterization of Nickel oxide (NiO) nanoparticles. Nanosized Nickel oxide powder was successfully synthesized using a simple and low cast sol-gel method. This method is environment friendly requiring no expensive chemicals and is time saving. The sol-gel method was accompanied by the formation of precipitates which were dried and calcined at $550^{\circ} \mathrm{C}$ to get nickel oxide nanoparticles. The synthesized nanopowder was characterized by $\mathrm{X}$-ray diffraction (XRD), Scanning Electron Microscopy (SEM), and Energy Dispersive Spectroscopy (EDX).
\end{abstract}

Keywords: Synthesis, nickel oxide (NiO), nanoparticles, sol-gel method, energy dispersive spectroscopy.

\section{Introduction}

$\mathbf{N}$ anotechnology is the manipulation and production of nanoparticles which have novel properties significantly different from their bulk counterparts. These properties as is mentioned in the literature are the result of the fascinating phenomena such as quantum confinement effect and surface plasmon resonance effect [1]. Metallic nanoparticles (nanosized metals) because of their sharp size distribution gained much popularity and thus have unlocked new horizons in nanotechnology [2]. In recent years much attention has been focused on the synthesis of metal oxide nanoparticles because of their large surface areas and exceptional adsorptive properties [3]. Different synthesis methods are used for the synthesis of ultrafine $\mathrm{NiO}$ nanoparticles including microemulsion technique, spray pyrolysis, surfactant mediated method and simple liquid phase synthesis, electrochemical reduction, chemical reduction and sol-gel method [4,5]. Magnetic transition metal nanoparticles including $\mathrm{NiO}$ have wide range of applications in magnetic and electronic devices, solar energy collectors, battery electrodes, catalysis, permanent magnets, magnetic fluids, nickel cermet, electrochromic coatings and antiferromagnetic layers, These applications can be enhanced by controlling the particle size $[1,4,6,7]$.

$\mathrm{NiO}$ NPs were amalgamated by chemical reduction method using nickel chloride hexa hydrate as an antecedent and polyvinylpyrolidone as a capping agent [8]. Nickel nanoparticles were synthesized on large scale using anodic arc plasma method [9] and by solution reduction method using $\mathrm{Ni}\left(\mathrm{NO}_{3}\right)_{2} \cdot 6 \mathrm{H}_{2} \mathrm{O}$ and benzildiethylenetriamine as raw materials[10]. Sol-gel method was used to prepare NiO nanocatalysts using nickel nitrate hexahydrate and sodium dodecyl [11]. In many of the methods used above the main concern is to reduce the cost and to produce $\mathrm{NiO}$ powder for technological applications.

The objective of present work is to synthesize of nickel oxide nanoparticles by sol-gel method. This is simple and cost effective route because of use of inexpensive and few starting materials. By controlling structure, calcination temperature, and $\mathrm{PH}$ value we synthesized pure NiO NPs. There are various advantages of using sol-gel method such as homogeneous mixing, good crystallinity and uniform and sharp size distribution of synthesized nanoparticles. 


\section{Experimental}

In present study NiO NPs were synthesized by using Chemical (sol-gel). This study was carried out at Nanoscience and Technology department, National centre for Physics, QAU Islamabad and Department of Chemistry, University of Wah, Wah Cantt. During this work all chemicals were purchased from local market of Sigma-Aldrich. These were AR-Grade and there was no need of further purification. The Chemicals used were, Nickel (ii) nitrate hexahydrate and $0.5 \mathrm{M}$ sodium hydroxide. We used deionized water throughout the experiment.

\subsection{Chemical synthesis}

In this method aqueous solution of nickel nitrate hexahydrate was prepared by dissolving $3-4 \mathrm{~g}$ of salt in $100 \mathrm{ml}$ of deionized water. We stirred the solution to dissolve the salt completely. The salt solution was titrated by adding $0.5 \mathrm{M} \mathrm{NaOH}$ drop wise from burette with constant stirring. Frequently we checked the $\mathrm{PH}$. The precipitates were formed when $\mathrm{PH}$ was 11 . The color of precipitates of nickel was green. These precipitates were washed 4-5 times with de-ionized water and then were dried at $95^{\circ} \mathrm{C}$ to remove moisture. Dried precipitates were calcined at $550^{\circ} \mathrm{C}$ for three hours in a muffle furnace. The calcined material was grinded by mortar and pistil and samples were prepared. Main reactions during procedure can be summarized as follows:

$$
\begin{gathered}
\mathrm{Ni}^{2+}+2 \mathrm{OH}^{1-}+\mathrm{xH}_{2} \mathrm{O} \longrightarrow \mathrm{Ni}(\mathrm{OH})_{2} \cdot \mathrm{xH}_{2} \mathrm{O}_{(s)} \downarrow \\
\mathrm{Ni}(\mathrm{OH})_{2} \cdot \mathrm{xH}_{2} \mathrm{O}_{(s)} \longrightarrow \mathrm{Ni}(\mathrm{OH})_{2(s)}+\mathrm{xH}_{2} \mathrm{O}_{(g)} \\
\mathrm{Ni}(\mathrm{OH})_{2(s)} \longrightarrow \mathrm{NiO}_{(s)}+\mathrm{H}_{2} \mathrm{O}_{(g)}
\end{gathered}
$$

We analyzed nanoparticles by using XRD model D8 ADVANCE BRUKER X-Source Copper/(anode). The samples were characterized by XRD and their sizes were noted in nanometer. The synthesized NPs were also characterized by SEM performed on SEM, TESCAN, VEGA3 placed at Advanced Energy and Material lab NUST. The EDX was done on EDX Oxford placed at Fracture Mechanics and Fatigue Lab, Mechanical Engineering Department, UET Taxila.

\section{Results and discussions}

\subsection{X-ray diffraction (XRD)}

X-ray diffraction is used to investigate structure, phase transformation, and crystallite size of nanoparticles (see Figure 1. It is also helpful to find preferred orientation in powdered solid samples. This technique provides much information on lattice parameters and crystal size. Crystal sizes can be calculated using Scherrer Equation; $\mathrm{D}=\mathrm{K} \lambda \backslash \beta \operatorname{COS} \theta$. In this technique a beam of $\mathrm{X}$-rays fall on electrons of crystals and is scattered and provides elaborate crystal structure [12].

Table 1. XRD Data of NiO Nanoparticles

\begin{tabular}{||cccc||}
\hline PEAKS & $2 \theta$ POSITION & hkl VALUES & d-SPACING \\
\hline \hline 1 & 37.248 & 111 & 2.4120 \\
2 & 43.275 & 200 & 2.0890 \\
3 & 62.878 & 220 & 1.4768 \\
\hline
\end{tabular}

The diffraction peaks for $\mathrm{NiO}$ nanoparticles were matched with JCPDF \# 47-1049. Peaks were sharp and prominent representing formation of NiO NPs. The peaks line width described nanoparticle nature of sample. Average particle size for NiO NPs was found to be $45 \mathrm{~nm}$ according to the XRD data. The appearance of crystallographic planes such as 111, 200, and 220 indicate crystallization of NiO NPs.

\subsection{Scanning electron microscopy (SEM)}

Scanning electron microscopy offers several advantages to determine size, shape and morphology of nanoparticles. The dry powder is placed on a holder and coated with gold. The surface of powder is then 


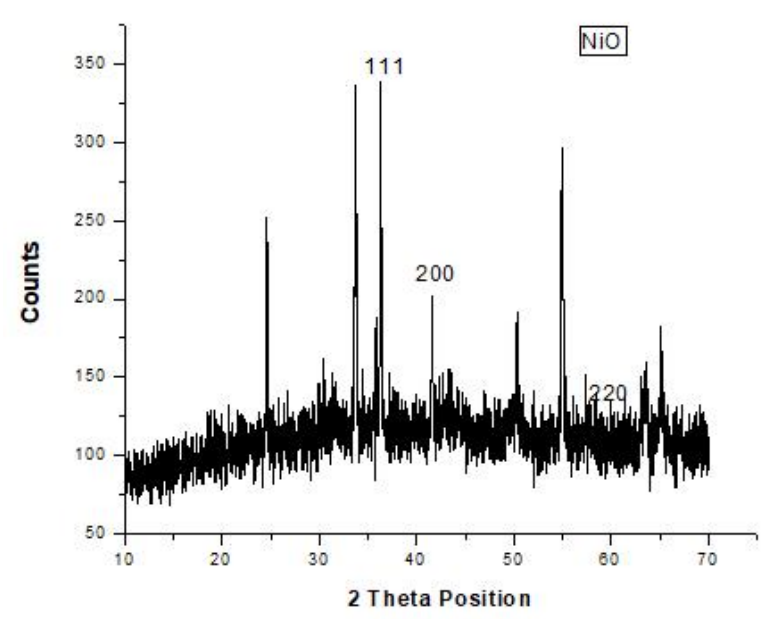

Figure 1. XRD Spectrum of NiO NPs

scanned with fine beam of electrons for analysis [13]. Variety of signals is generated and reveals information related to the texture, composition, crystalline structure of material [12].

SEM study of NiO NPs showed successful formation of spherical black uniform sized nanoparticles because of selection of suitable calcination temperature. Thus NiO NPs with an average diameter of 40nm which is very near to its XRD size of $45 \mathrm{~nm}$ were synthesized by using optimum calcination temperature of $550^{\circ} \mathrm{C}$. The formed NPs show agglomeration at different locations due to large surface energy and high reactivity.

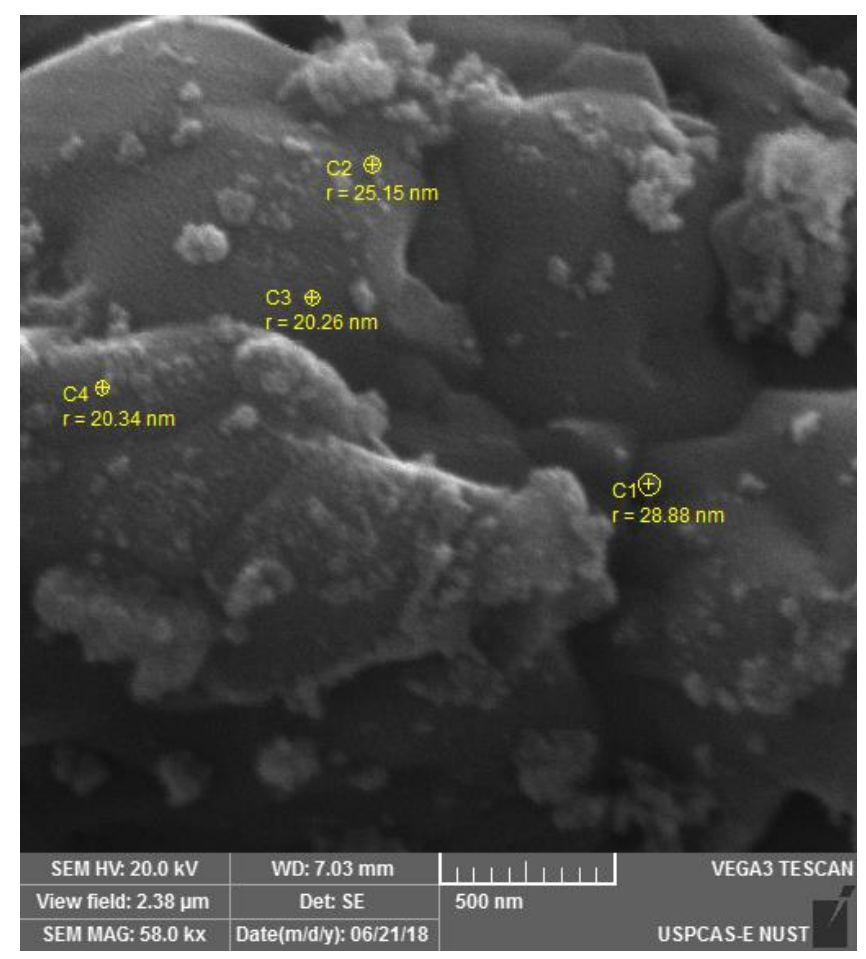

Figure 2. SEM Micrograph of NiO NPs (500nm)

\subsection{Energy dispersive X-Ray spectroscopy (EDX)}

The elemental composition of synthesized materials is determined by EDX, a micro analytical technique used in association with SEM [12]. The EDX detects X-rays emitted from sample when electrons are bombarded on material surface. Data about chemical composition is provided by measuring the intensity and energy of 
the signal. The EDX spectrum shows frequency of x-rays in counts for each energy level. The intensity of the peak gives information about the amount of the element in sample [14].

Elemental analysis of NiO NPs demonstrated that synthesized NiO NPs consisted of $67.3 \% \mathrm{Ni}$ content and $32.7 \% \mathrm{O}$ content without any trace of other materials

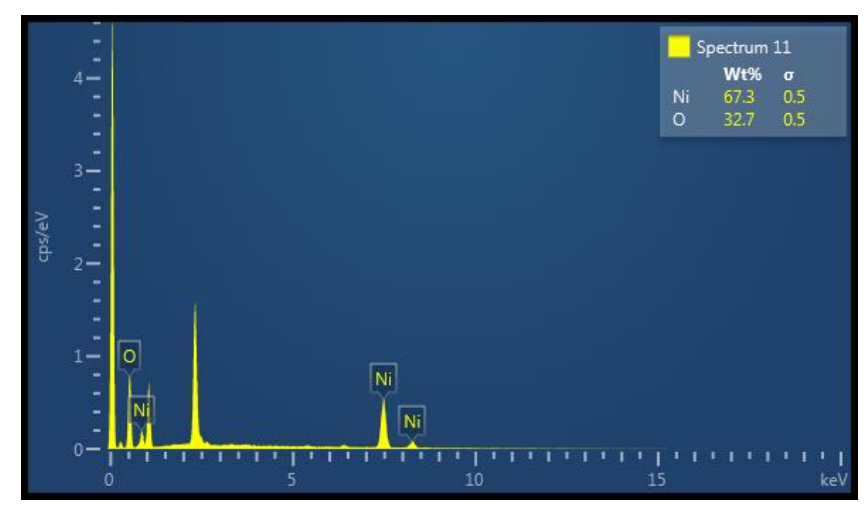

Figure 3. EDX Spectrum of NIO NPs

\section{Conclusion}

TThe NiO NPs were successfully fabricated via sol-gel method using nickel nitrate hexahydrate and sodium hydroxide as main materials. The results indicated the formation of pure NiO NPs without any impurity. The morphological study showed nanorange of particles and Elemental analysis successfully traced $\mathrm{Ni}$ and $\mathrm{O}$ elements. Nickel Oxide nanoparticles have promising signs in the fields of light weight optics, lithium ion batteries, wastewater purification, and semiconductor materials.

Acknowledgments: We acknowledge the provision of services of NS \& TD, NCP, QAU Islamabad

Author Contributions: All authors contributed equally to the writing of this paper. All authors read and approved the final manuscript.

Conflicts of Interest: "The authors declare no conflict of interest."

\section{References}

[1] Salvadori, M. R., Ando, R. A., Nascimento, C. A. O., \& Corrêa, B. (2015). Extra and intracellular synthesis of nickel oxide nanoparticles mediated by dead fungal biomass. PloS one, 10(6), e0129799.

[2] Harish K K, Nagasamy V, Himangshu B,Anuttam K. Metallic Nanoparticle: A Review. Biomed J Sci ETech Res 4(2)2018. BJSTR.MS.ID.001011

[3] Rahdar, A., Aliahmad, M., \& Azizi, Y. (2015). NiO nanoparticles: synthesis and characterization. Journal of Nanostructures, 5(2), 145-151.

[4] Theivasanthi, T., \& Alagar, M. (2012). Chemical capping synthesis of nickel oxide nanoparticles and their characterizations studies. arXiv preprint arXiv:1212.4595.

[5] Davar, F., Fereshteh, Z., \& Salavati-Niasari, M. (2009). Nanoparticles Ni and NiO: synthesis, characterization and magnetic properties. Journal of Alloys and Compounds, 476(1-2), 797-801.

[6] Pooja Khandagale and Dipali Shinde. (2017);ăSynthesis \& characterization of nickel oxide nanoparticles by using coprecipitation method.ăInternational Journal of Advanced Research., ă5ă(5). 1333-1338

[7] Zorkipli, N. N. M., Kaus, N. H. M., \& Mohamad, A. A. (2016). Synthesis of NiO nanoparticles through sol-gel method. Procedia Chemistry, 19, 626-631.

[8] Salahuddin, N. A., El-Kemary, M., \& Ibrahim, E. M. (2015). Synthesis and characterization of ZnO nanoparticles via precipitation method: effect of annealing temperature on particle size. $\breve{N}$ Nanoscience and Nanotechnology, $\breve{a} 5(4), 82-88$.

[9] Wang, H., Kou, X., Zhang, J., \& Li, J. (2008). Large scale synthesis and characterization of Ni nanoparticles by solution reduction method. Bulletin of Materials Science, 31(1), 97-100

[10] Chandra, S., Kumar, A., \& Tomar, P. K. (2014). Synthesis of Ni nanoparticles and their characterizations. Journal of Saudi Chemical Society, 18(5), 437-442.

[11] Chaudhary, R. G., Tanna, J. A., Gandhare, N. V., Rai, A. R., \& Juneja, H. D. (2015). Synthesis of nickel nanoparticles: Microscopic investigation, an efficient catalyst and effective antibacterial activity. Adv. Mater. Lett, 6(11), 990-998. 
[12] Ungula, J. (2015). Growth and characterization of $\mathrm{ZnO}$ nanoparticles by sol-gel process (Doctoral dissertation, University of the Free State (Qwaqwa Campus)).

[13] Bhatia, S. (2016). Nanoparticles types, classification, characterization, fabrication methods and drug delivery applications. In Natural polymer drug delivery systems (pp. 33-93). Springer, Cham.

[14] Srivastava, R. (2012). Synthesis and characterization techniques of nanomaterials. International Journal of Green Nanotechnology, 4(1), 17-27.

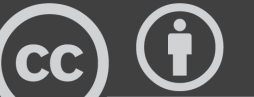

BY

(C) 2019 by the authors; licensee PSRP, Lahore, Pakistan. This article is an open access article distributed under the terms and conditions of the Creative Commons Attribution (CC-BY) license (http://creativecommons.org/licenses/by/4.0/). 